\title{
REALIDADE AUMENTADA E O CÁLCULO DE MEDIDA DE ÁREA NO ENSINO SUPERIOR
}

\author{
AUGMENTED REALITY AND THE CALCULATION OF AREA MEASUREMENT \\ IN HIGHER EDUCATION
}

\author{
REALIDAD AUMENTADA Y CÁLCULO DE LA MEDIDA DE ÁREA EN \\ EDUCACIÓN SUPERIOR
}

\author{
Kayla Rocha Braga' ${ }^{1}$ (D) \\ José Messildo Viana Nunes ${ }^{2}$ (D) 9
}

\begin{abstract}
RESUMO
Apresenta-se, nesse artigo, uma proposta de uso da tecnologia Realidade Aumentada tomando como referência o ensino de medida de área. A intervenção foi efetivada numa turma de graduação do curso de Engenharia Elétrica da Universidade Federal do Maranhão. A fundamentação teórica se ampara na Abordagem Instrumental, que permitiu analisar o uso da tecnologia Realidade Aumentada como ferramenta de ensino no nível superior. A pesquisa está estruturada em duas etapas: a instrumentalização, que se deu em dois momentos, sendo o primeiro de formação quanto ao uso da Realidade Aumentada, e o segundo, de instalação de um software de desenvolvimento da Realidade Aumentada; e a segunda, de instrumentação, com a resolução das tarefas, sem e com o uso da Realidade Aumentada, seguida de entrevista com os participantes. Os dados obtidos na pesquisa nos possibilitaram identificar a transição de artefato a instrumento com o uso da tecnologia da Realidade Aumentada, bem como constatar que a planta baixa ao ser projetada em 3D fez com que os alunos mudassem de ideia sobre a necessidade de considerar a espessura nos cálculos realizados, passando a estabelecer uma melhor relação com a noção de área e medida de área.
\end{abstract}

Palavras-chave: Realidade Aumentada. Vuforia. Engenharia. Cálculo de Medida de Área.

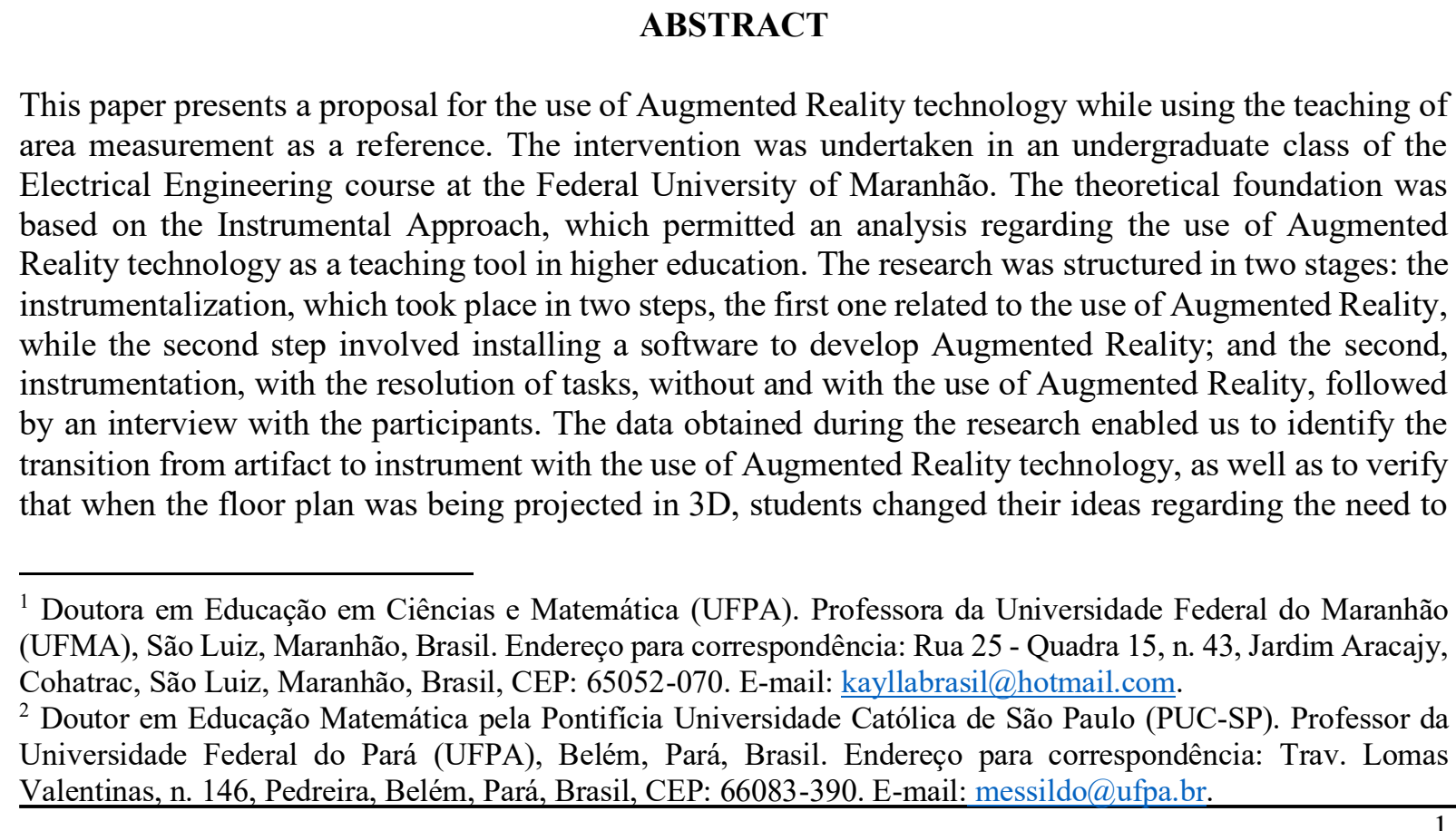


consider the thickness in the calculations undertaken, thereby starting to establish a better relationship with the notion of area and area measurement.

Keywords: Augmented Reality. Vuforia. Engineering. Area Measurement Calculation.

\section{RESUMEN}

En este trabajo se presenta una propuesta para el uso de la tecnología de Realidad Aumentada tomando como referencia la enseñanza de la medición de áreas. La intervención se llevó a cabo en una clase de pregrado del curso de Ingeniería Eléctrica de la Universidad Federal de Maranhão. El fundamento teórico se basó en el Enfoque Instrumental, que permitió un análisis sobre el uso de la tecnología de Realidad Aumentada como herramienta de enseñanza en la educación superior. La investigación se estructuró en dos etapas: la instrumentalización, que se desarrolló en dos pasos, el primero relacionado con el uso de la Realidad Aumentada, mientras que el segundo paso consistió en instalar un software para desarrollar la Realidad Aumentada; y el segundo, instrumentación, con la resolución de tareas, sin y con el uso de Realidad Aumentada, seguido de una entrevista a los participantes. Los datos obtenidos durante la investigación nos permitieron identificar la transición de artefacto a instrumento con el uso de la tecnología de Realidad Aumentada, así como verificar que cuando se proyectaba la planta en 3D, los estudiantes cambiaban sus ideas sobre la necesidad de considerar la espesor en los cálculos realizados, comenzando así a establecer una mejor relación con la noción de área y medición de área.

Palabras clave: Realidad Aumentada. Vuforia. Ingenieria. Cálculo de Medición de Área.

\section{INTRODUÇÃO}

A Realidade Aumentada (RA) é uma evolução da Realidade Virtual (RV). A RA, além das características comuns da RV, que são, segundo Braga (2012), a interatividade, a geração por computador, e os gráficos representados em $3 \mathrm{D}$, ainda traz outros traços próprios, em que o principal deles é o de transportar o ambiente virtual para a realidade física.

Segundo Ribeiro e Zorzal (2011), as bases da RA surgiram na década de 1960, porém, somente na de 1980, foi que se produziu o primeiro projeto de RA misturando elementos virtuais com o ambiente físico do usuário. A RA permite a sobreposição de objetos e ambientes virtuais com o ambiente físico por meio de algum dispositivo tecnológico. A RA possibilita interações tangíveis mais fáceis e naturais sem o uso de equipamentos especiais, como um visor colocado na cabeça ou luvas com sensores. Vale destacar que a RA pode ser usada em qualquer ambiente (fechado ou aberto), sendo, portanto, mais abrangente e universal.

Kirner e Tori (2006, p. 29) diferenciam RV de RA. Para eles:

[...] Diferentemente da realidade virtual, que transporta o usuário para o ambiente virtual, a realidade aumentada mantém o usuário no seu ambiente físico e transporta o ambiente virtual para o espaço do usuário, permitindo a interação com o mundo virtual, de maneira mais natural e sem necessidade de treinamento ou adaptação. 
No contexto educacional, a aplicação da RA tem ocorrido de forma mais abrangente em escolas mais estruturadas e equipadas, já que os aplicativos disponíveis, em sua maioria, requerem mais recursos financeiros. No entanto, tem-se evidenciado a criação de aplicativos gratuitos que abordam a Realidade Aumentada em universidades públicas por pesquisadores. (SANTOS, 2015; SILVA, 2012; DUNCAN, 2014).

Dessa forma, a educação pode ser vista como um processo de descoberta, exploração e observação. Tais ações são de fundamental importância para a construção do conhecimento e, nesse contexto, a possibilidade de simular situações e experimentos que, de maneira real não seriam possíveis ou viáveis, propicia grandes avanços no processo educacional. A RA torna-se uma ferramenta que favorece a realização de experiências lúdicas, de forma mais intuitiva e interativa, suportando a exploração de ambientes, processos ou objetos, de uma forma totalmente inovadora, e, em nosso entender devem ser articuladas/inseridas aos métodos mais tradicionais como o quadro de escrever, os livros, os filmes etc. (KIRNER; TORI, 2006).

Assim, muitas são as vantagens da RA para a educação, e no ensino de Matemática, em particular, os benefícios advindos das RA auxiliam particularmente no ensino de Geometria. Isto porque um dos problemas tradicionalmente apresentados na literatura é o fato de os livros serem em 2D, o que dificulta ao aluno a sensação tridimensional de imersão e profundidade, enquanto na RA é possível se fazer um estudo mais aprofundado das figuras tridimensionais. A exemplo disso, temos o software Construct $3 D^{3}$, que é uma ferramenta de construção de Geometria tridimensional projetada especificamente para o ensino de Matemática e Geometria, baseada em técnicas de RA (AZUMA et al., 2001). Uma das vantagens de usar a RA nesta situação é que os alunos podem visualizar e explorar o ambiente em 3D.

Para aplicação de RA em dispositivos móveis, segundo Zuñiga Torres (2008), são indicados três tipos distintos de dispositivos, são eles: a) PDA $;{ }^{4}$ b) UMPC $;{ }^{5}$ c) smartphones. ${ }^{6}$

\footnotetext{
${ }^{3} \mathrm{O}$ sistema Construct3D é uma ferramenta colaborativa tridimensional projetada para ensino de Matemática e Geometria (LINDEMANN, 2014).

${ }^{4} \mathrm{O}$ PDA (Personal Digital Assistant), também conhecido como palmtop, designa um pequeno equipamento com funcionalidades de computador. Apesar da sua pequena dimensão, os PDA estão dotados de grande capacidade de processamento possuindo funções de agenda e de escritório com a possibilidade de acesso à Internet e de interconexão com computadores e redes informáticas sem fio. A despeito do crescimento extremamente elevado dos PDA, estes se tornaram gradualmente ultrapassados (PEREIRA, 2019, não paginado).

${ }^{5} \mathrm{O}$ Ultra Mobile PC (UMPC) é um pequeno computador de mão com a capacidade de executar o sistema operacional Windows. Embora esteja mais próximo do tamanho de um palmtop do que de um laptop, um Ultra Mobile PC oferece mais funcionalidade que um palmtop. Em 2006, o UMPC foi lançado como um esforço colaborativo entre Microsoft, Intel, Samsung e vários outros fabricantes. Mesmo com especificações aprimoradas, no entanto, a categoria UMPC está perdendo seu mercado em favor de tablets populares. (TECHOPEDIA, [201?], não paginado).

${ }^{6} \mathrm{O}$ smartphone é um telefone celular e significa "telefone inteligente", em português. Evolução dos telefones comuns, os smartphones são mais caros que os celulares, mas trazem tecnologias que vão muito além de ligações
} 
Os PDA e os UMPC possuem poder de processamento, tamanho e peso, além de uma grande capacidade de inserir dados por meio de uma caneta digital, facilitando assim, o modo de interação com o dispositivo. Contudo, não são muito utilizados em aplicações de RA devido ao alto custo e por possuírem um maior consumo de bateria.

Já os smartphones, que possuem a combinação das melhores características presentes nos outros dois dispositivos móveis já citados, são uma excelente plataforma para o desenvolvimento das aplicações de RA, das mais simples às mais complexas, incluindo conexão de rede local (Intranet/Internet - WLAN), por meio de interfaces de comunicação sem

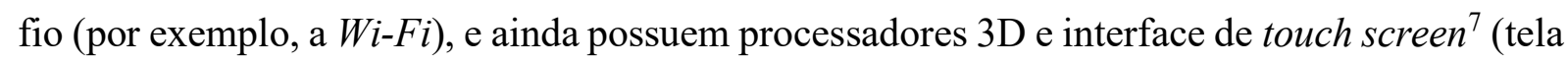
sensível ao toque).

Portanto, Zuñiga Torres (2008, p. 8-9) acrescenta ainda que, independentemente do dispositivo móvel que se escolha para uma aplicação de RA, há um fluxo de processamento que se resume em três fases, as quais são: “aquisição de imagem do mundo real (captura de vídeo); reconhecimento de marcadores; a mistura do mundo real e virtual (renderização ${ }^{8}$ e apresentação de imagens virtuais)."

Nesse contexto, para nossa pesquisa, escolhemos o dispositivo móvel smartphone, pois acreditamos que seja o que melhor se adapta à proposta dessa pesquisa, bem como por ser mais acessível aos alunos (DANTAS; TEIXEIRA-OLIVEIRA, 2020).

Para a execução de um software em RA, são necessários um computador, uma câmera e um display. Segundo Braga (2012), a função da câmera é rastrear um sinal (que pode ser uma figura impressa, uma luva especial ou até mesmo as mãos) e seu movimento, comumente um marcador (Figura 1) manipulado pelo usuário para que a sua posição seja identificada e essa informação seja enviada continuamente para processamento.

e mensagens de texto. Geralmente são maiores em tamanho, com telas sensíveis ao toque e possuem um sistema operacional complexo, como o Android, iOS ou Windows Phone. Em outras palavras, são telefones com a complexidade tecnológica de computadores.

${ }^{7}$ A tela sensível ao toque surgiu, de forma geral, como uma necessidade de desvincular-se de fios, componentes e botões físicos, assim como elevar um simples telefone celular a outro patamar. Essa tecnologia evidencia-se a partir do momento em que "a tela se impõe como uma interface generalizada aberta ao mundo, fornecendo continuamente informações [...]” (LIPOVETSKY; SERROY, 2009, p. 257 apud PEDROZA; NICOLAU, 2015, p. 8).

${ }^{8}$ A renderização é a atividade de geração de imagens ou vídeos por meio de um computador. A renderização de cenas tridimensionais (3D) é uma tarefa bem conhecida em diferentes tipos de aplicação, como jogos e ambientes virtuais em geral. A partir de um modelo 3D são produzidas imagens baseadas nas informações tridimensionais deste modelo, como geometria, ponto de vista, texturas e efeitos de iluminação (SANTOS, 2009). 


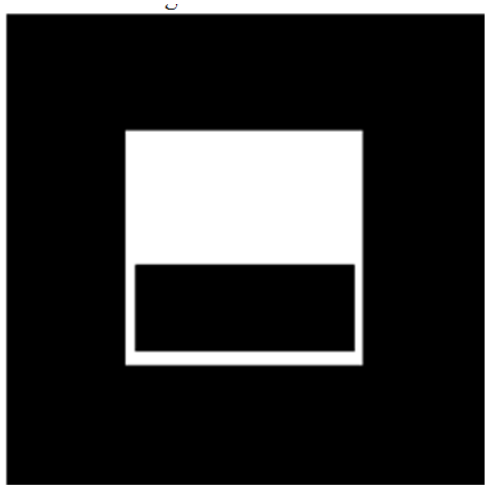

Figura 1 - Marcador Fonte: Braga (2012, p. 68)

Ainda conforme Bimber e Raskar (2005), a Unidade Central de Processamento (Central Processing Unit - CPU) $)^{9}$ identifica o marcador e procura pelo comando a ser executado ou por uma imagem, que pode ser em 3D estática ou animação, uma imagem fotográfica ou até mesmo um vídeo armazenada no disco rígido que lhe tenha sido atribuída, com o objetivo de ser enviada ao display. Estes, por sua vez, são sistemas de formação de imagem que utilizam um conjunto de componentes ópticos, eletrônicos e mecânicos para gerar imagens em algum ponto entre os olhos do observador e o objeto físico a ser aumentado para exibição conjunta com a imagem do marcador e tudo o mais que estiver sendo capturado pela câmera (BIMBER; RASKAR, 2005).

Costa (2009) considera que, à medida que mais educadores compreenderem sobre como as pessoas aprendem por meio da interação e a tecnologia evoluir, os ambientes virtuais em RV e RA serão vistos com mais frequência em nossas escolas e universidades, dando suporte à educação no processo de ensino e aprendizagem.

Vale destacar ainda que, segundo Carmigniani e Furht (2011), a RA também tem potencial para permitir a acessibilidade a usuários cegos ou com baixa visão e surdos. Nesse sentido, Vicentini et al. (2006) fizeram uso da RA para criar uma interface computacional de geração de Ambientes Virtuais de Aprendizagem (AVA) para surdos e mudos.

No ensino superior, a RA vem sendo cada vez mais utilizada no processo de ensino de diversas áreas, dentre as quais estão as Engenharias. No Catálogo de Teses e Dissertações da Coordenação de Aperfeiçoamento de Pessoal de Nível Superior (CAPES), no período compreendido entre 2014 e 2018, encontramos 95 pesquisas, entre dissertações e teses, que abordam a RA ${ }^{10}$ nas Engenharias como Grande Área; e 63 pesquisas no quesito Engenharia

\footnotetext{
${ }^{9}$ A unidade central de processamento (CPU) de um computador é uma peça de hardware que executa as instruções de um programa de computador. Ele executa as operações básicas aritméticas, lógicas e de entrada/saída de um sistema de computador. A CPU é como o cérebro do computador - cada instrução, por mais simples que seja, precisa passar por ela.

${ }^{10} \mathrm{O}$ indexador utilizado nessa busca foi "Realidade Aumentada".
} 
Elétrica. Constatamos que em nenhuma delas aborda-se o cálculo de medida de área, nem tampouco usam o quadro teórico da Rabardel para refletir sobre o uso da RA.

Segundo Douady e Perrin-Glorian (1989), dentre os erros mais frequentes no estudo de área e sua medida, destacam-se as compreensões sobre as concepções geométricas e as concepções numéricas. Para as autoras, esses erros decorrem da dificuldade dos mesmos em distinguir: área de superfície e área de números. Com o intuito de superar os obstáculos que originam dos erros anunciados, elas lançam as seguintes hipóteses: a primeira é desenvolver o conceito de área como grandeza ajuda os alunos a estabelecer relações entre os quadros geométricos e numéricos; e a segunda é que uma identificação precoce entre as grandezas e os números induzem os alunos a fazer confusões entre perímetro e área.

Constatamos em algumas pesquisas, cujo enfoque se deu sobre o ensino de noções de área e sua medida, que os alunos apresentam dificuldades, tais como: não dissociam área de perímetro; aplicam indevidamente as fórmulas de cálculo de área das figuras planas; utilizam de forma equivocada as unidades de medidas (BALTAR, 1996; FACCO, 2003; BALDINI, 2004; NUNES, 2011). Estes indicadores apontam para uma problemática no ensino e na aprendizagem desse objeto de estudo na escola básica e mesmo na educação superior (CHIUMMO, 19998; MOREIRA, 2010). Nesse sentido, elegemos tarefas que favoreçam a articulação entre os diferentes quadros -geométricos, numéricos e das grandezas (DOUADY; PERIN-GLORIAN, 1989).

Logo, temos como objetivo apresentar uma proposta de uso da tecnologia Realidade Aumentada tomando como referência o ensino de área e sua medida.

\section{O SOFTWARE VUFORIA}

A RA, já explicitada, é a junção de elementos virtuais num cenário real, e para que a RA seja possível, é necessário um dispositivo que tenha a capacidade de capturar um vídeo e exibir o mesmo ao usuário em tempo real. Nesse dispositivo é utilizado um software que insere os elementos virtuais, sendo que estes podem ser manipulados pelo usuário, seja na tela do dispositivo, ou pela interação com o elemento virtual.

Anteriormente, só era possível a utilização da RA em computadores, mas com a evolução da tecnologia, hoje já é possível empregá-la também em dispositivos móveis, tais como smartphones. Isso se dá pelo avanço da computação móvel e aumento da qualidade e da velocidade de processamento desses dispositivos. 
Uma das vantagens de desenvolver RA em dispositivos como esses, é que há uma grande quantidade desses aparelhos no mercado, os quais chegam mais facilmente às mãos dos usuários, devido não só à sua popularidade e facilidade de manuseio e de transporte, mas, principalmente, ao seu baixo valor de compra, se comparados aos computadores ultramodernos. Vale mencionar que esses dispositivos têm evoluído tanto que adquiriram características de pequenos computadores com sistemas operacionais cada vez mais poderosos e uma grande disponibilidade de aplicativos.

Destacamos que entre os sistemas operacionais, um dos mais utilizados, segundo Bergamaschi e Morais (2014), é o Android $^{11}$, desenvolvido pela empresa Google, baseado na plataforma Linux que permite aos desenvolvedores de software usar todas as funcionalidades que o aparelho possa oferecer.

O sistema operacional Android possui um Software Development Kit ${ }^{12}-S D K$ que, conforme Bergamaschi e Morais (2014), possibilita o desenvolvimento de aplicativos para a plataforma. O SDK utiliza a linguagem de programação Java ${ }^{13}$ e vários de seus componentes para a criação de aplicativos e RA. Assim, utilizando de frameworks (conjunto de códigos) para auxiliar em características mais específicas, como é o caso da biblioteca Artoolkit que é, segundo Kirner e Tori (2006, p. 30), um software disponível gratuitamente no site do laboratório da Universidade de Washington. Artoolkit é uma biblioteca de software baseada nas linguagens $\mathrm{C}^{14}$ e $\mathrm{C}++$ usadas para o desenvolvimento de aplicações de RA.

Entretanto, em nossa pesquisa utilizamos outro software, o Vuforia, que segundo Silva et al. (2008), é um software multiplataforma que propicia usar a RA em qualquer recurso, sejam smartphones, computadores ou tablets. A nossa escolha se justifica tanto pela facilidade de acesso dos alunos a esses recursos tecnológicos, como também por esta ser uma ferramenta completa que possui diversas funcionalidades de RA. Além disso, Gruber et al. (2016) citam que o Vuforia ainda viabiliza criar aplicações e jogos para dispositivos móveis de maneira

\begin{tabular}{l}
11 O Android é uma pilha de software com base em Linux de código aberto criada para diversos dispositivos e \\
fatores de forma. O Android vem com um conjunto de aplicativos principais para e-mail, envio de SMS, \\
calendários, navegador de internet, contatos etc. Os aplicativos inclusos na plataforma não têm status especial \\
entre os aplicativos que o usuário opta por instalar. (DEVELOPER, [201-?], não paginado). \\
${ }^{2}$ O Android SDK ou Kit de Desenvolvimento de Software para Android é um pacote com diversas ferramentas \\
utilizadas pelo Android e pelos desenvolvedores Android. (CORDEIRO, [201-?], não paginado). \\
${ }_{13}$ Java é uma linguagem de programação e plataforma computacional lançada pela primeira vez pela Sun \\
Microsystems em 1995. (JAVA. [201-?], não paginado). \\
${ }^{14}$ A linguagem C é uma linguagem de alto nivel, genérica. Foi desenvolvida por programadores para \\
programadores tendo como meta características de flexibilidade e portabilidade. O C é uma linguagem que nasceu \\
juntamente com o advento da teoria de linguagem estruturada e do computador pessoal. Assim, tornou-se \\
rapidamente uma linguagem "popular" entre os programadores. O C foi usado para desenvolver o sistema \\
operacional UNIX e hoje está sendo usada para desenvolver novas linguagens, entre elas a linguagem C++e Java. \\
\hline
\end{tabular} 
intuitiva, bem como suporta reconhecimento de imagens, $Q R \operatorname{codes}^{15}$, textos e superfícies em formato cilíndrico.

O software Vuforia é um kit de desenvolvimento de software SDK, que de acordo Bergamaschi e Morais (2014), foi desenvolvido pela empresa americana Qualcomm para trabalhar RA e tem como suporte as plataformas Android, $\mathrm{iOS}^{16}$ e Unity $3 D^{17}$. O Vuforia é indicado para o desenvolvimento de aplicações de RA por ser gratuito e de código aberto, cujas funções são usadas em programas de aplicativos desenvolvidos pelo usuário. Os usuários, inclusive os não programadores, podem elaborar aplicações de RA individuais e colaborativas.

A maioria das aplicações em RA, segundo Gruber et al. (2016), utilizam marcadores para posicionar os objetos em 3D no mundo real. O Vuforia se baseia no uso desses marcadores na imagem capturada por uma câmera, fazendo com que os objetos virtuais se sobreponham sobre os marcadores ou imagens pré-configuradas para posicionar um objeto 3D em tempo real.

Gruber et al. (2016), acrescentam ainda que esses marcadores podem ser feitos em papel com formatos geométricos, os quais em sua maioria, são nas cores preta e branca. Através do reconhecimento de padrões, os marcadores são utilizados para calcular posições e mostrar os objetos 3D.

Esses marcadores permitem também, segundo Zuñiga Torres (2008, p. 40), definir um sistema de coordenadas espaciais e a orientação dos objetos (do mundo real) a partir do ponto de vista do usuário, a fim de identificar alterações de posicionamento e sobrepor as imagens virtuais nos objetos do mundo real de forma adequada. Zuñiga Torres (2008) complementa que existem mais de trinta marcadores, dentre esses, apenas seis foram adaptados para a aplicação de RA em dispositivos móveis. Ele os divide em duas categorias:

a) Database 2D Barcodes: citamos como exemplo, o QR Code, o VSCode e Data Matrix. Estes, por sua vez, são utilizados junto às câmeras dos celulares para reconhecer e decodificar dados.

b) Index-based 2Dbarcodes: citamos como exemplo o Visual Code, ShotCode e o ColorCode. Estes foram desenvolvidos tendo em consideração as limitações das

${ }^{15} \mathrm{O}$ QR code (Quick Response) consiste em um gráfico 2D de uma caixa preto e branca que contém informações
pré-estabelecidas como textos, páginas da internet, SMS ou números de telefone.
${ }^{16}$ Conhecido como um dos melhores sistemas operacionais do mundo, o iOS foi desenvolvido pela Apple. Famoso
por sua segurança, estabilidade e confiança não é raro vermos episódios colocando o sistema como o melhor e
mais protegido do mundo. O iOS foi lançado originalmente em 2007 com o primeiro iPhone. (MEYER, 2018, não
paginado).
${ }^{17}$ O Unity $3 D$ se apresenta como um Game Engine, ou motor de jogo, mas na realidade é muito mais do que isso.
A ferramenta possui um estilo de programação e organização dos projetos todo especial, além de muito simples.
O Unity se propõe a ser um modelo para a criação de jogos de aventura. Tudo isso está permeado por uma
capacidade gráfica muito grande. (GASPAROTTO, 2014, não paginado). 
câmeras dos telefones celulares, permitindo acessar uma menor quantidade de dados.

Destacamos aqui que todos os marcadores apresentados possuem suas próprias ferramentas e suporte necessários para seu reconhecimento. Para desenvolvermos a aplicação em RA, escolhemos o software Unity3D por suportar programação para a plataforma Android. É um software gratuito e de código aberto utilizado para criar objetos em 3D com animações, efeitos visuais e aplicações interativas.

Ainda utilizamos o software Sweet Home $3 D^{18}$, que também é gratuito e de código aberto para uso em design de interiores, oferecendo uma série de recursos e ferramentas para a criação de ambientes bi e tridimensionais com o intuito de, inicialmente, nos familiarizarmos com o uso de plantas em 3D e nos orientarmos na aplicação de cálculo de área, por exemplo, no conteúdo de Luminotécnica, quando o aluno da Engenharia Elétrica irá calcular a área para definir o número de lâmpadas num determinado ambiente. Destacamos que em nossa pesquisa, nosso aluno não precisa saber programar, pois esses softwares são de fácil manuseio.

\section{ABORDAGEM INSTRUMENTAL}

Para fundamentar a pesquisa, no que tange ao uso de softwares na aprendizagem de Matemática, e, no nosso caso, mais especificamente no estudo de cálculo de medida de área, utilizamos a Abordagem Instrumental de Rabardel (1995).

A Abordagem Instrumental é procedente de trabalhos em Ergonomia Cognitiva ${ }^{19}$ e se refere à aprendizagem da utilização de ferramentas tecnológicas. O ponto de partida dessa teoria é a ideia de que uma ferramenta não é, automaticamente, um instrumento eficaz e prático. Um martelo, por exemplo, é um objeto sem significado, salvo quando se tem algo (apropriado ao instrumento) para aprofundar, inserir, moldar, transformando-o, assim, em um instrumento útil. Da mesma forma, algumas ferramentas são mais apropriadas que outras, dependendo do tipo de utilização a que se propõem.

Rabardel (1995) descreve a relação que existe entre o sujeito, o artefato e os esquemas de utilização da seguinte forma: sujeito é o indivíduo ou grupo de indivíduos que desenvolve (em) a ação ou é (são) escolhido (os) para o estudo; artefato é o dispositivo que pode ser

\footnotetext{
${ }^{18}$ Sweet Home 3D é uma aplicação de design interior que ajuda você colocar suas mobílias em sua casa em um plano 2D com uma visualização em 3D. (SWEET HOME, 2019).

${ }^{19}$ A Ergonomia Cognitiva refere-se aos processos mentais, tais como percepção, memória, raciocínio e resposta motora conforme afetem as interações entre seres humanos e outros elementos de um sistema. Aqui, destacamos a interação homem e computador. (ASSOCIACCÃO BRASILEIRA DE ERGONOMIA, [201-?]).
} 
material, por exemplo, o lápis ou o computador, ou simbólico que pode ser um gráfico, ou seja, o que é usado como meio da ação pelo sujeito e os esquemas de utilização, conforme Salazar (2009), tomados da Teoria dos Campos Conceituais de Vergnaud.

A abordagem instrumental estuda os aspectos próprios que existem no artefato e no instrumento, diferenciando o artefato, o instrumento e os processos que envolvem a transformação progressiva do artefato em instrumento, denominada por Rabardel (1995), de Gênese Instrumental. De acordo com esse autor, tal processo busca a integração entre as características dos artefatos e as atividades do sujeito, em outras palavras, as potencialidades e limitações desse artefato e os conhecimentos e métodos de trabalho desse sujeito.

Para Rabardel (1995), os artefatos são vistos sob dois pontos de vista:

a) Técnico - o artefato é um sistema técnico, cujas especificidades, estruturas e sistema operacional obedecem a regras e limitações relacionadas à atividade do homem em contato com ele (o artefato);

b) De suas funções - o artefato é considerado como um sistema de funcionamento, ou seja, o que ele produz.

Apesar das diferenças significativas entre as concepções de artefato e instrumentos, o autor, no entanto, distingue os três polos: o sujeito, o instrumento e o objeto. Para Rabardel (1995, p. 52):

- O sujeito é o usuário, o operador, o trabalhador, o agente etc.

- O instrumento é a ferramenta, a máquina, o sistema, o utensílio, o produto etc.

- O objeto é sobre o qual a ação por meio do instrumento é dirigida (material, real, objeto da atividade, objeto de trabalho, outro sujeito etc.).

Rabardel (1995) propõe o modelo SAI - Situações de Atividades Instrumentais (Figura 2), apresentando a relação entre o sujeito e o objeto mediado pelo instrumento.

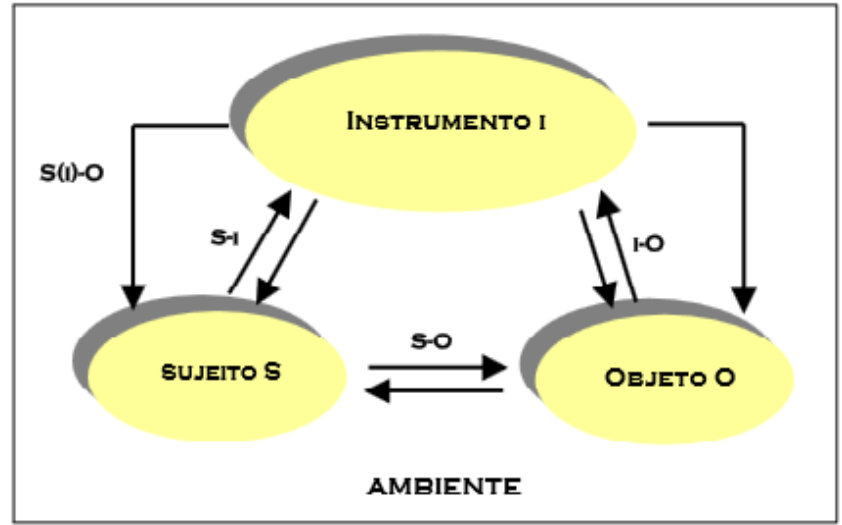

Figura 2 - Modelo de situações de atividades instrumentais Fonte: Rabardel (1995, p. 65) 
O modelo SAI evidencia as interações que há entre:

a) Sujeito-objeto [S-O];

b) Sujeito-instrumento [S-i];

c) Instrumento-objeto [i-O];

d) Sujeito-objeto mediado pelo instrumento [S (i)-O].

Essas interações são desenvolvidas em um ambiente formado pelo conjunto de condições que o sujeito deve considerar ao desenvolver uma tarefa. Segundo Rabardel (1995), o modelo SAI possibilita fazer uma primeira aproximação sobre a tarefa instrumentada. Em outras palavras, podemos dizer que esse modelo nos dará subsídios para analisarmos uma tarefa mediada pelo instrumento.

De acordo como autor acima citado, o modelo SAI pode orientar e auxiliar o professor a desenvolver uma tarefa em sala de aula e organizá-la melhor para atingir o objetivo proposto. Esse mesmo teórico destaca que o instrumento, como ente mediador do sujeito e o objeto, possui duas orientações: em relação à objeto-sujeito, o instrumento é o meio que permite o conhecimento do objeto, enquanto na orientação sujeito-objeto, o instrumento é o meio da ação transformadora dirigida sobre o objeto.

De acordo com Rabardel (1995, p. 95), o instrumento é uma entidade mista com dois componentes. Ele diz que, por um lado, o artefato é produzido para o sujeito, e por outro, os esquemas de utilização associados são resultantes de uma construção própria do sujeito ou de uma apropriação de esquemas de utilização já existentes. A partir do momento em que o sujeito começa a conhecer o instrumento, novos esquemas são desenvolvidos e novas funções vão se organizando e integrando a esse instrumento, que aos poucos se modificam. Vale ressaltar que cada sujeito constrói e modifica seu próprio instrumento.

Tomemos, como exemplo, o caso do software da Realidade Aumentada. Consideremos um indivíduo que desconhece um determinado software. Ao entrar em contato com esse recurso tecnológico, que não sabe manipulá-lo, está diante de um artefato. À medida que ele começa a conhecer o recurso, descobre como é seu funcionamento e elabora situações de uso do software, pois o indivíduo, segundo Bittar (2011), está desenvolvendo e agregando ao artefato esquemas de utilização e, então, o mesmo é transformado em instrumento para este professor. Quanto mais maior a sua utilização, mais esquemas podem ser construídos, agregados ao software e o professor terá, então, um novo instrumento. 
Esses esquemas desenvolvidos pelo sujeito, segundo Rabardel (1995), podem ser esquema de uso ou esquema de ação instrumentada. O primeiro se refere às tarefas ligadas diretamente ao artefato (clicar num aplicativo na tela do computador) e o segundo às tarefas relacionadas ao objetivo da ação (aprender a usar as ferramentas do aplicativo para realizar a tarefa). Esse último esquema vai se constituindo em técnicas que permitem resolver eficientemente algumas tarefas.

Urge destacar que num determinado momento o esquema de ação instrumentada para poderá se transformar em um esquema de uso, pois a técnica que passa a ser automatizada para o sujeito pode ser interpretada como tal. O processo de elaboração do instrumento pelo sujeito é chamado de gênese instrumental. A despeito desse processo, Rabardel (1995, p. 111) descreve que:

\begin{abstract}
A instrumentalização concerne à emergência e à evolução dos componentes artefato do instrumento: seleção, reagrupamento, produção e instituição de funções, transformações do artefato [...] que prolongam a concepção inicial dos artefatos. A instrumentação é relativa à emergência e à evolução dos esquemas de utilização: sua constituição, seu funcionamento, sua evolução assim como a assimilação de artefatos novos aos esquemas já constituídos.
\end{abstract}

Observamos que um instrumento pode ser elaborado e reelaborado pelo sujeito ao longo das tarefas realizadas com o artefato. É oportuno notar que, segundo o supracitado autor, uma vez que o artefato sofreu a ação do sujeito, passa a ser um instrumento.

\title{
4 ASPECTOS METODOLÓGICOS
}

A pesquisa foi desenvolvida no Laboratório de Informática do Curso de Matemática (LabMat) de uma universidade pública do Maranhão com uma turma composta de 35 alunos de graduação em Engenharia Elétrica cursando a disciplina Instalações Elétricas, cuja ênfase nesse artigo foi o conteúdo Luminotécnica ${ }^{20}$. A intervenção foi mediada pela primeira autora dessa pesquisa. Dentre os alunos, onze aceitaram participar da pesquisa e foram identificados alfabeticamente e em ordem crescente para preservação de suas identidades. Os recortes das respostas (escritas e faladas) dos participantes da pesquisa correspondem aos alunos nomeados

\footnotetext{
${ }^{20}$ A Luminotécnica é o estudo minucioso das técnicas das fontes de iluminação artificial, por meio da energia elétrica (LUMINOTÉCNICA, 2009). Para que o engenheiro eletricista faça em seu projeto de iluminação os cálculos luminotécnicos de um determinado ambiente, ele deve tomar conhecimento das normas da Associação Brasileira de Normas Técnicas (ABNT). Vamos destacar aqui em nossa pesquisa, a NBR 5410, edição 2004, referente aos projetos de instalações elétricas.
} 
de A, B, D e F, pois grande parte das respostas foram semelhantes e por isso, elegemos as que representavam as falas em geral da turma.

Para a realização da pesquisa aqui descrita, utilizamos como os seguintes instrumentos de coleta de dados: tarefas impressas em papel A4 e entrevistas semiestruturadas aplicadas aos participantes a fim de identificar a estratégia de resolução das tarefas com e sem o uso do artefato RA. Os encontros foram registrados em áudio e vídeo. A análise dos dados se deu por meio da utilização de noções constituintes da Teoria Instrumental e do Modelo SAI, as quais nos permitiram analisar a relação sujeito-instrumento-objeto. A intervenção da pesquisa está organizada em fases e subdividida em momentos.

\section{RESULTADOS}

Iniciamos pela fase de instrumentalização, que segundo Rabardel (1995), concerne ao conhecimento do artefato, no que diz respeito à sua seleção, reagrupamento, produção e instituição de funções bem como de transformações desse mesmo artefato.

A fase 1 abrangeu dois momentos voltados à organização do esquema de uso que, ainda conforme o autor, se refere às tarefas ligadas diretamente ao artefato.

Nesse sentido, realizamos o primeiro momento com o intuito de proporcionar que os alunos conheçam o artefato, assim como suas funcionalidades e aplicabilidade.

Portanto, reproduzimos um debate com especialista da área, intitulado "Realidade Virtual e Realidade Aumentada" do Prof. Dr. Márcio Sarroglia Pinho, disponibilizado no $Y_{\text {Youtube }}^{21}$. A apresentação do vídeo se deu no Laboratório de Matemática (LabMat), local onde aconteceram os encontros da pesquisa com os alunos.

Ademais, por se tratar de um assunto tão específico da área da computação, convidamos uma programadora para colaborar com a pesquisa. Durante a reprodução, os alunos interagiam com a programadora a partir de questionamentos do tipo: O que é renderização; O que é API? Qual a diferença entre API e OPENGL 22 ?; Por que triangularização?; O OPENG é só para a placa gráfica?

Ainda nessa fase, realizamos o segundo momento, o qual se deu por meio da instalação, do software Vuforia View Enterprise pelos alunos nos seus smartphones com o auxílio e orientações da programadora e seu posterior uso. Aqui, enfocamos a Gênese Instrumental, na

\footnotetext{
${ }^{21}$ Disponível em: https://www.youtube.com/watch?reload=9\&v=DB6WwSvKHCo Acesso em: 17/12/2018.

22 "API dedicada a gráficos 3D, muito conhecida. Ela é muito usada em jogos e nos mais variados aplicativos comerciais ou não.” (DESENVOLVIMENTO DE JOGOS, 2018, não paginado).
} 
qual os alunos puderam compreender melhor seu esquema de uso a partir do processo de instalação e manuseio do software. Nesse momento, os alunos tiveram o primeiro contato com o artefato - a tecnologia RA, o que, no modelo SAI, se refere à relação Sujeito-Instrumento [Si].

Na segunda fase, englobando o terceiro e o quarto momento, realizamos a aplicação das tarefas $\mathrm{T}_{1}$ e $\mathrm{T}_{2}$, respectivamente em que $\mathrm{T}_{1}=\left\{\mathrm{t}_{11}, \mathrm{t}_{12}, \mathrm{t}_{13}, \mathrm{t}_{14}, \mathrm{t}_{15}, \mathrm{t}_{16}, \mathrm{t}_{17}\right\}, \mathrm{e} \mathrm{T}_{2}=\left\{\mathrm{t}_{21}, \mathrm{t}_{22}, \mathrm{t}_{23}, \mathrm{t}_{24}\right.$, $\left.\mathrm{t}_{25}, \mathrm{t}_{26}, \mathrm{t}_{27}, \mathrm{t}_{28}\right\}$. Tivemos como objetivos, nessas etapas: analisar como os alunos responderiam sem o uso da ferramenta computacional, ou seja, com uso de lápis e papel, as tarefas (T) e as subtarefas $(\mathrm{t})$ associadas a T; e investigar as estratégias utilizadas pelos alunos para a resolução das mesmas.

Partindo desse pressuposto, assumimos como ponto de partida a seguinte situação fundamental (BROUSSEAU, 1996): "Distribuir as luminárias no espaço". A tarefa $\left(\mathrm{T}_{1}\right)$ : "Calcular a medida da área da planta baixa" se deu a fim de engendrar a problemática referente à situação de ponto de partida proposta. Para isso, apresentamos as seguintes subtarefas $(t)$ : $t_{11}$ Calcular a medida da área do quarto $1 ; \mathrm{t}_{12}$ Calcular a medida da área do quarto $2 ; \mathrm{t}_{13}$ Calcular a medida da área da sala; $\mathrm{t}_{14}$ Calcular a medida da área do banheiro; $\mathrm{t}_{15}$ Calcular a medida da área da garagem; $\mathrm{t}_{16}$ Calcular a medida da área da cozinha; $\mathrm{t}_{17}$ Calcular a medida da área da área de serviço.

Para o desenvolvimento de um projeto elétrico, é necessário determinar a quantidade de lâmpadas que fornecerão um nível de iluminação adequada ao ambiente. A determinação dessa quantidade pode ser feita de três formas, são elas: pela carga mínima exigida por normas (ABNT NBR 5410), pelo método de lúmens e pelo método das cavidades zonais. ${ }^{23}$ Em nossa pesquisa, consideramos, para determinação do número de pontos de luz, somente a primeira forma (CREDER, 2016).

Assim, os alunos iniciaram a resolução das tarefas pertencentes à $T_{1}$, em que lhes foi apresentada a seguinte planta baixa (Figura 3):

\footnotetext{
${ }^{23}$ Baseiam-se em níveis de iluminância para a determinação da quantidade de lâmpadas e luminárias. Nessa mesma característica o método de lumens também se baseia em nível de iluminância. (FIORINI, 2006). 


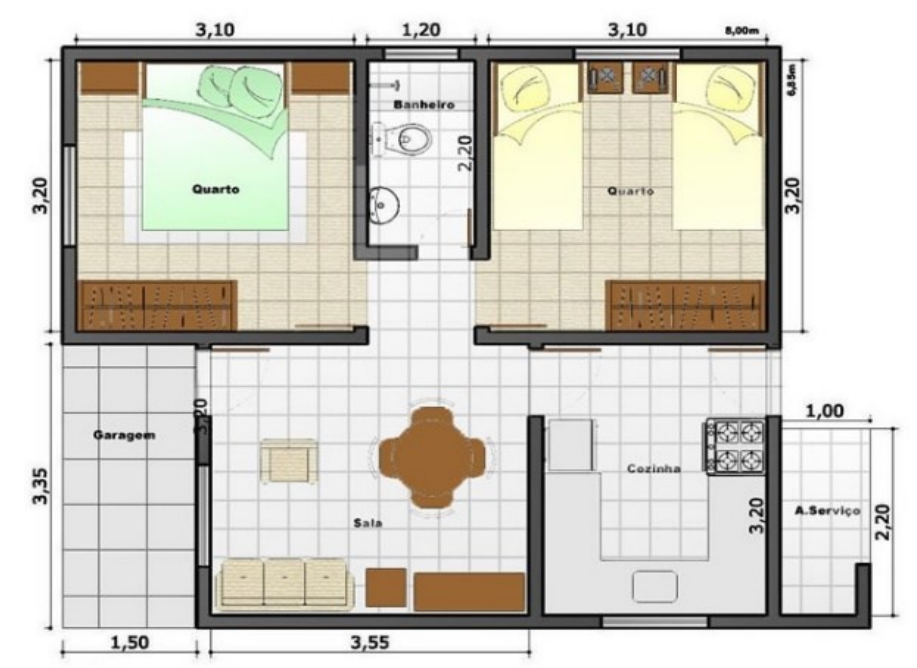

Figura 3 - Planta baixa residencial Fonte: Elaborado pelos autores

De posse da planta baixa, os alunos responderam às subtarefas propostas. No decorrer do processo, quando da resolução de $\mathrm{t}_{16}$, um dos alunos nos perguntou se influenciaria a espessura das paredes no cálculo dessa medida de área, ao que houve imediata manifestação dos demais colegas, alguns declarando ser necessário considerá-la e outros discordando. Compreendendo que a nossa intervenção poderia influenciar nas escolhas, estratégias e ações dos participantes, não nos manifestamos, deixando-os livres para realizarem os cálculos como melhor entendessem.

Na subtarefa $t_{16}$ foi omitida uma das dimensões das medidas necessárias para o cálculo, considerando a fórmula $b \times h$, para que os alunos encontrassem a dimensão oculta, nesse caso, a do comprimento, com o objetivo de identificar estratégias para a resolução da atividade.

$\mathrm{Na}$ última etapa realizada, os alunos utilizaram a RA na resolução com os mesmos comandos da Tarefa $\mathrm{T}_{1}$, que analisamos com base no referencial teórico da Teoria Instrumental (RABARDEL, 1995).

Assim, nesse último encontro, os participantes, mais uma vez, foram convidados a realizar a resolução da tarefa $\mathrm{T}_{2}$. Para a resolução de tais atividades, da mesma forma, lhes foi apresentada a planta baixa que segue (Figura 4): 


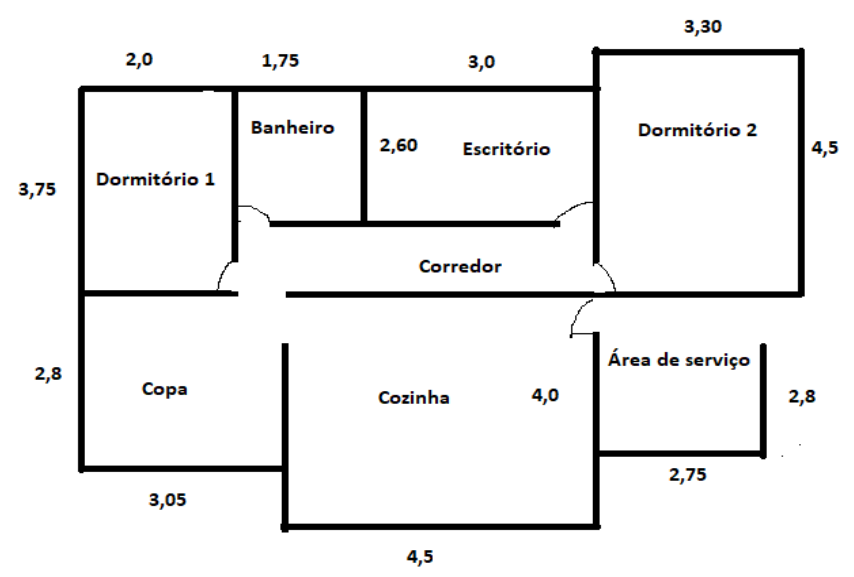

Figura 4 - Planta baixa da tarefa 2

Fonte: Autoria própria (2018)

De posse da planta baixa, os alunos responderam a tarefa $T_{2}=\left\{t_{21}, t_{22}, t_{23}, t_{24}, t_{25}, t_{26}, t_{27}\right.$, $\left.\mathrm{t}_{28}\right\}$, que consistiu, mais uma vez, em calcular a medida de área de cada cômodo, sendo que, nessa ocasião, não houve questionamento quanto a incluir ou não a espessura da parede.

O processo de produção de dados, nesta última etapa, ocorreu em três momentos distintos e sequenciados entre si: a) resolução das tarefas com base apenas na planta baixa disponibilizada; b) utilização do artefato RA para visualização da planta (disponibilizada no primeiro momento) projetada em 3D; e c) entrevista. Para execução desse processo, foram utilizadas duas salas, sendo denominadas de sala 01 e sala 02 , respectivamente. A sala 01 foi utilizada para a resolução das tarefas, realizada de forma individualizada; e a sala 02 para a efetivação dos demais momentos: as entrevistas, o posterior uso do artefato pelo aluno e as entrevistas.

Assim, após o primeiro momento realizado na sala 01, cada aluno foi encaminhado individualmente para a sala 02 (Figura 5), onde foi entrevistado, sendo na sequência, lhe sugerido o uso do artefato RA para a visualização da planta projetada em 3D, e, por último, aplicada a entrevista. Vale ressaltar que as medidas apresentadas na planta projetada em 3D são as mesmas aplicadas à planta baixa, disponibilizadas no primeiro momento do processo. 

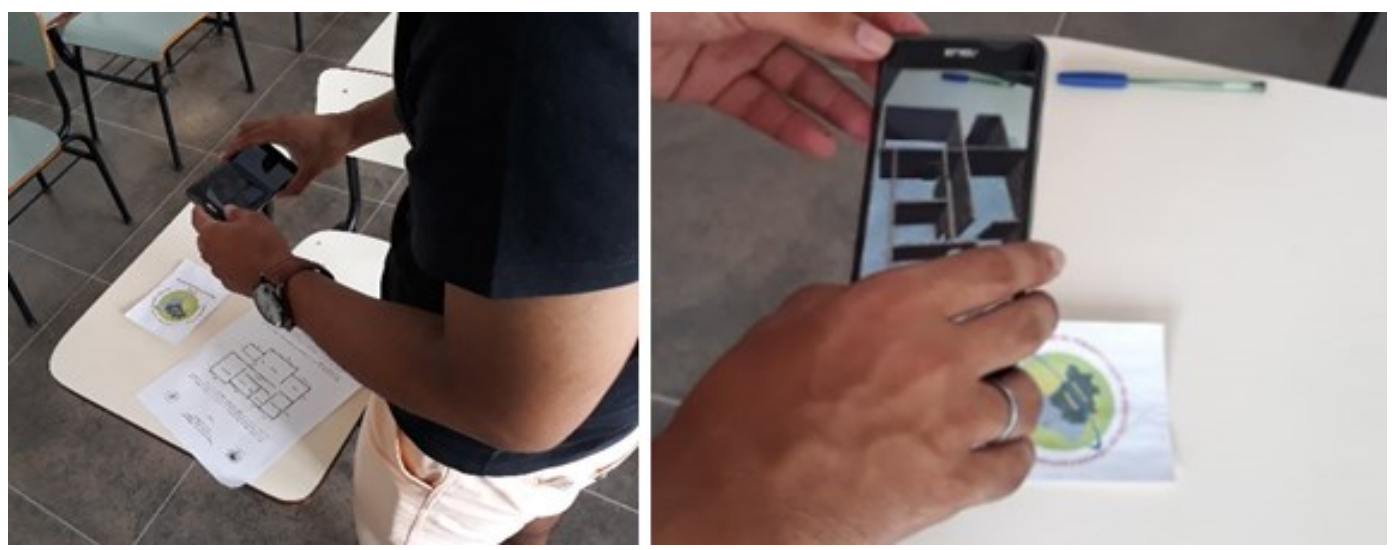

Figura 5 - Alunos aplicando a RA Fonte: Dados da pesquisa

As entrevistas semiestruturadas realizadas no segundo momento, logo após a aplicação das tarefas correspondentes a $\mathrm{T}_{2}$, buscaram responder aos seguintes questionamentos:

a) Explique, de forma geral, como você realizou os cálculos da planta baixa?

b) Há algum cálculo que difere dos demais?

c) Em algum dos cálculos, você incluiu a espessura da parede?

d) Você acha que essa espessura influencia no cálculo da medida de área?

Em se tratando das entrevistas realizadas após o uso do artefato pelo aluno, seus objetivos eram obter respostas para as seguintes questões:

a) Do relatado anteriormente, na primeira entrevista, você alteraria alguma afirmação que você tenha feito?

b) Quanto ao uso do recurso Realidade Aumentada, você considera que este pode ou não ajudar na compreensão da noção de área e, consequentemente, no cálculo da medida da área?

No primeiro momento, quando da resolução das tarefas com base na planta baixa disponibilizada na tarefa $\mathrm{t}_{15}$, omitimos uma das dimensões das medidas necessárias para $\mathrm{o}$ cálculo, para que os alunos encontrassem a dimensão oculta, nesse caso, a da largura, com o objetivo de identificar estratégias na resolução das atividades.

Nesse último momento, quando do uso do artefato RA para a visualização da planta projetada em 3D, os alunos puderam elaborar seus esquemas de ação instrumentada que, segundo Rabardel (1995), se refere às tarefas ligadas ao objetivo da ação com o uso propriamente dito do artefato, ou seja, seu manuseio. 
O artefato agora passa a ser visto sob a perspectiva de suas funções, sendo considerado como um sistema de funcionamento, em outras palavras, o que ele produz. Torna-se, então, instrumento, pois passa a mediar a relação sujeito-objeto. No modelo SAI de Rabardel (1995), as interações dessa relação são assim representadas: [S(i)-O].

\section{ANÁLISES DAS FALAS DOS ALUNOS ANTES E DEPOIS DO USO DA RA}

Na primeira situação, a qual chamamos de "corredor", o aluno dispõe de papel A4, lápis e régua. Na segunda situação, a qual intitulamos de "corredor 3D", o aluno dispõe do RA, por meio do software Vuforia e um marcador.

a) Situação corredor: os alunos (A, B, D e F), de maneira geral, para determinar a área total do corredor observaram as dimensões e realizaram tais ações: adicionaram o comprimento do banheiro $(1,75 \mathrm{~m})$ e do escritório $(3,0 \mathrm{~m})$; multiplicaram pela subtração da largura do dormitório $1(3,75 \mathrm{~m})$ com outra dimensão do banheiro $(2,60 \mathrm{~m})$;

b) Situação corredor 3D: os alunos (A, B, D e F), individualmente, numa sala à parte, denominada de sala 2, posicionou o celular sobre o marcador, tocou na tela para obter a projeção; e, em seguida, rotacionou, ampliou e reduziu a imagem, a fim de se movimentar na planta. Desta maneira, analisou e determinou as dimensões do corredor para estabelecer a área deste cômodo.

A RA, que na primeira fase foi considerada como artefato, passa a ser agora, instrumento sob o ponto de vista de suas funções, ou seja, o que esse instrumento produz (RABARDEL, 1995). A RA passa a mediar a relação sujeito-objeto e a interação dessa relação sujeitoinstrumento-objeto são assim representadas [S(i) - O].

Em nossa pesquisa, os alunos visualizaram uma planta baixa em $2 \mathrm{D}$ e fizeram afirmações não condizentes com o real. Pudemos constatar tais dados por meio da aplicação de entrevista, a qual foi realizada logo após a execução das tarefas sem/com a intervenção da RA. Destacamos aqui as perguntas e as respostas dos alunos:

\subsection{Respostas dadas pelos alunos antes da projeção em 3D}

Explique, de forma geral, como você realizou os cálculos da planta baixa? (Pergunta da pesquisadora, 2018). 
Em geral, boa parte dos cômodos foi realizada apenas o produto das medidas do comprimento e da largura de cada um dos cômodos. (Resposta do aluno A, 2018).

De forma geral, eu utilizei o cálculo da área dos retângulos, porque a gente vê que as figuras são retângulos, então utilizei o cálculo da área do retângulo, base vezes altura. (Resposta do aluno B, 2018). Multipliquei base vezes altura. (Resposta do aluno D, 2018).

Em geral, só multipliquei as dimensões, base e altura [sic]. (Resposta do aluno F, 2018).

Há algum cálculo que difere dos demais? (Pergunta da pesquisadora, 2018).

O que mais se diferiu foi o do corredor, porque ele não tinha as medidas. Para encontrar as medidas foi utilizada a adição de $1,75 \mathrm{~m}$ (que seria a medida do banheiro) e $3 \mathrm{~m}$ que seria a medida do escritório e para chegar à largura foi utilizada a subtração de 3,75 (que é a largura do dormitório) por 2,7m que é a largura do banheiro [sic]. (Resposta do aluno A, 2018).

Sim! No corredor, porque no corredor a gente tem que combinar medidas de outros compartimentos para depois encontrar a área. Por exemplo, o que eu utilizei como base fazendo o somatório das duas medidas, da base do banheiro e da base do escritório, e quanto à altura, foi a subtração de outras duas medidas que foi a do dormitório um com a medida da altura do banheiro [sic]. (Resposta do aluno B, 2018).

O cálculo diferente foi do corredor, porque não foram dadas as medidas de imediato, tive que encontrar [sic]. (Resposta do aluno D, 2018).

O único diferente foi do corredor [sic]. (Resposta do aluno F, 2018).

Em algum dos cálculos, você incluiu a espessura da parede? (Pergunta da pesquisadora, 2018).

Não foi incluída a espessura da parede [sic]. (Resposta do aluno A, 2018).

Não cheguei a incluir a espessura da parede [sic]. (Resposta do aluno B, 2018).

Não! (Resposta do aluno D, 2018).

Não! (Resposta do aluno F, 2018).

Você acha que essa espessura influencia no cálculo da medida de área? (Pergunta da pesquisadora, 2018).

Como no caso aqui estamos trabalhando só com números inteiros e medidas a partir de $4 m^{2}$, não vai fazer uma diferença tão grande no cálculo geral [sic]. (Resposta do aluno A, 2018).

Eu acho que não, porque a gente estava trabalhando aqui apenas a área que seria utilizada, vamos dizer assim, a espessura da parede não vai influenciar com a área que vou utilizar no corredor [sic]. (Resposta do aluno B, 2018).

Acho que não, é muito pequena a espessura da parede [sic]. (Resposta do aluno D, 2018).

Não, acredito que não! [sic]. (Resposta do aluno F, 2018).

\subsection{Respostas dadas pelos alunos após a projeção em 3D}

Quando a planta baixa foi projetada em 3D, a nova imagem da figura fez com que os alunos mudassem de resposta, passando a compreender a noção de medida de área com mais clareza.

Do relatado anteriormente, na primeira entrevista, você alteraria alguma afirmação que você tenha feito? (Pergunta da pesquisadora, 2018).

Sim! Pela planta eu não teria percebido também as diferenças da parede. Fica bem mais claro quando vemos montada a casa. Com certeza agora dá para ver a influência da espessura da parede. Agora dá para ver claramente. Eu acho que talvez na situação do exercício, considerando poucas casas decimais e está trabalhando com medições a partir de $4 \mathrm{~m}^{2}$, a espessura da parede não ficaria com um enfoque tão significativo. Mas percebi que alterou a área do corredor. Na planta baixa parecia pequena, mas no tamanho real, não é [sic]. (Resposta do aluno A, 2018).

Acho que mudaria em relação à espessura da parede, porque aparentemente ela parece influenciar. Porque pelo desenho, sem ser pela aplicação do software, a ideia de $15 \mathrm{~cm}$ parecia ser pequeno demais. Tinha a ideia de $15 \mathrm{~cm}$ ser insignificante. Mas agora não, alterou a área [sic]. (Resposta do aluno B, 2018).

Sim! Eu adicionaria a espessura da parede. Alterou o cálculo da área [sic]. (Resposta do aluno D, 2018). 
Sim, eu mudaria meus cálculos ao considerar a espessura da parede. Muda a área [sic]. (Resposta do aluno F, 2018).

Quanto ao uso do recurso da Realidade Aumentada, você considera que este pode ou não ajudar na compreensão da noção de área e, consequentemente, no cálculo de área? (Pergunta da pesquisadora, 2018).

Ajuda sim, sem dúvida! Dá para perceber melhor a influência dessas espessuras. Mesmo a casa sendo relativamente simples, de um andar só, e se tivéssemos trabalhado com uma planta maior e mais complexa, a espessura da parede poderia fazer uma diferença bem grande [sic]. (Resposta do aluno A, 2018).

Através do software nós temos uma ideia melhor do que seriam esses $15 \mathrm{~cm}$. Inicialmente eu imaginava o corredor maior, agora eu consigo ver ele num espaço bem menor do que eu imaginava que ele seria. Eu vejo no tamanho real a casa. Vejo que mudou a área, e se mudou a área, mudou também o cálculo que fiz [sic]. (Resposta do aluno B, 2018).

Sim, com certeza! Ajuda a gente a perceber que área não era o que eu pensava, ela é bem menor [sic]. (Resposta do aluno D, 2018).

Claro! A Realidade Aumentada me ajudou a ver a área que eu não conseguia. (Resposta do aluno F, 2018).

Assim, a resolução dos conjuntos de tarefas favoreceu a compreensão da noção de área e sua medida e possibilitou aos alunos, por meio de diferentes respostas, fazer a distinção entre área, medida de área e de superfície, levando-os a reconhecerem a noção de área como grandeza.

\section{CONSIDERAÇÕES}

O processo de resolução das tarefas ocorreu, primeiramente, apenas com uso do papel e lápis sem a intervenção da RA. E em seguida, com o uso do papel e lápis com a intervenção da RA. Como as tarefas propostas em T1 e T2 se relacionavam, basicamente, ao cálculo da medida de área dos cômodos de uma planta baixa, então a resolução destas, apenas com papel e lápis, se resumiu ao uso da fórmula $b \times h$, com exceção dos cálculos das áreas da cozinha e do corredor, cujas dimensões (comprimento, na área da cozinha, e largura, na área do corredor) foram ocultadas propositadamente para provocar uma reflexão sobre como realizar o cálculo de área sem todas as dimensões dadas.

Na resolução dessa, os mesmos apresentaram técnicas e respostas diferentes, utilizando para isso, apenas as operações matemáticas básicas (nesse caso, somente soma, subtração e multiplicação), alguns considerando, em determinados momentos, a espessura da parede, outros a desconsiderando por completo.

A proposição do uso da RA se deu em função das dificuldades encontradas pelos alunos em distinguir os conceitos de área e superfície. A utilização da RA como instrumento tem base em Rabardel (1995), que define o instrumento como o meio que permite, ao mesmo tempo, o 
conhecimento do objeto e a ação transformadora dirigida sobre esse objeto, no caso, medida de área. Dessa forma, a RA como instrumento atua em duas dimensões: a de entidade intermediária, na qual o instrumento é o mediador da relação sujeito-objeto; e a meio de ação, onde ele pode ser visto como: instrumento material de transformação do objeto; instrumento psicológico, ou seja, como decisão cognitiva do sujeito; e instrumento semiótico, na interação semiótica com um objeto semiótico.

Em $\mathrm{T}_{2}$, quando da resolução das tarefas com o uso da RA, em que a planta baixa foi projetada em 3D, a nova imagem da figura fez com que os alunos mudassem de resposta, passando a estabelecer uma melhor relação com a noção de área e medida de área, ao perceberem a significância da medida da espessura da parede no cálculo total da medida da área (em torno de $15 \mathrm{~cm})$.

Logo, apresentamos uma proposta de uso da tecnologia Realidade Aumentada tomando como referência o ensino de área e sua medida que se configurou nas tarefas envolvendo um problema de projeto de iluminação típico do contexto do curso de Engenharia Elétrica, abordando características específicas sobre o estudo de área como grandeza que favoreceu o estabelecimento de relações entre os quadros geométricos e numéricos.

Essa pesquisa não teve por objetivo findar no objeto pesquisado, mas ampliar futuramente no sentido de buscar respostas para a minimização das dificuldades apresentadas pelos alunos do ensino superior na compreensão da noção de área, nos campos numérico, geométrico e das grandezas, bem como no reconhecimento da distinção entre perímetro e área, área e superfície, e área e medida de área, que deveria ter sido apreendida na educação básica. Para uma próxima pesquisa, pode-se desenvolver uma proposta que possibilite aos alunos ampliar seus conhecimentos sobre a noção de área abrangendo o cálculo de área por meio da integral, assim como dos cálculos das curvas com o recurso da Realidade Aumentada.

\section{REFERÊNCIAS}

ASSOCIAÇÃO BRASILEIRA DE ERGONOMIA. O que é Ergonomia. [201-?]. Disponível em: http://www.abergo.org.br/internas.php?pg=o_que_e_ergonomia. Acesso em: 15 out. 2019.

ASSOCIAÇÃO BRASILEIRA DE NORMAS TÉCNICAS. NBR 5010: instalações elétricas de baixa tensão. Rio de Janeiro: ABNT, 2004. 209 p.

AZUMA, Ronald et al. Recent advances in augmented reality. IEEE Computer Graphics and Applications, California, v. 21, n. 6, p. 34-47, nov./dez. 2001. ISSN: 1558-1756. DOI: 
http://dx.doi.org/10.1109/38.963459. Disponível em:

https://ieeexplore.ieee.org/document/963459. Acesso em: 11 set. 2018.

BALDINI, Loreni Aparecida Ferreira. Construção do conceito de área e perímetro: uma sequência didática com auxílio de software de geometria dinâmica. 2004. 179 f. Dissertação (Mestrado em Ensino de Ciências e Educação Matemática) - Universidade Estadual de Londrina, Londrina, 2004. Disponível em:

http://www.educadores.diaadia.pr.gov.br/arquivos/File/2010/artigos teses/MATEMATICA/di ssertacao_loreni.pdf. Acesso em: 20 jul. 2018.

BALTAR, Paula Moreira. Enseignement et apprentissage de la notion d'aire de surfasse planes: une étude de l'acquisition des relation entre les longueurs et les aires aucollege. 1996. $241 \mathrm{f}$. Thèse (Doctorat Didactique Des Disciplines Scientifiques) - Université Joseph Fourier, Grenoble, 1996. Disponível em: http://www.theses.fr/1996GRE10193 Acesso em: 20 jul. 2018 .

BERGAMASCHI, Marcelo Pereira; MORAIS, Thamires Martins Augusto de. Estudo sobre a utilização de VUFORIA e Unity 3D com RA para dispositivos móveis. [Coleções WRVA], [Belo Horizonte], n. 31, 2014. Disponível em: http://www.lbd.dcc.ufmg.br/colecoes/wrva/2014/031.pdf. Acesso em: 1 ago. 2019.

BIMBER, Oliver; RASKAR, Ramesh. Spatial augmented reality: merging real and virtual worlds. Wellesley: A K Peters - Ltd, 2005. Disponível em:

http://pages.cs.wisc.edu/ dyer/cs534/papers/SAR.pdf. Acesso em: 11 out. 20198.

BITTAR, Marilena. A abordagem instrumental para o estudo da integração da tecnologia na prática pedagógica do professor de matemática. Educar em Revista, Curitiba: UFPR, n. especial 1, p. 157-171, 2011. Disponível em: http://www.scielo.br/pdf/er/nse1/11.pdf. Acesso em: 15 ago. 2019.

BRAGA, Marta Cristina Goulart. Diretrizes para o design de mídias em realidade aumentada. Orientadora: Profa. Dra. Vania Ribas Ulbricht. 2012. 241 f. Tese (Doutorado em Engenharia e Gestão do Conhecimento) - Centro Tecnológico, Programa de Pós-Graduação em Engenharia e Gestão do Conhecimento, Universidade Federal de Santa Catarina, Florianópolis, 2012. Disponível em:

http://repositorio.ufsc.br/xmlui/handle/123456789/99269. Acesso em: 15 jun. 2019.

BRASIL. Ministério da Educação. Base Nacional Comum Curricular. Brasília, DF: MEC, [2015]. (Documento preliminar). Disponível em:

http://basenacionalcomum.mec.gov.br/\#/site/inicio. Acesso em: 18 jan. 2018.

BRASIL. Ministério da Educação. Capes. Catálogo de Teses e Dissertações. 2019.

Disponível em: http://catalogodeteses.capes.gov.br/catalogo-teses/\#!/ Acesso em: 12 ago. 2019.

BRASIL. Ministério da Educação. Capes. Britannica Escola. 2018. Disponível em: https://escola.britannica.com.br/artigo/Al-Khwarizmi/481649. Acesso em: 12 ago. 2019.

BRASIL. Ministério da Educação. Ciências da Natureza, Matemática e suas Tecnologias. Brasília, DF: Ministério da Educação, Secretaria de Educação Básica, 2006. 135 p. 
(Orientações curriculares para o ensino médio; v. 2). Disponível em:

http://portal.mec.gov.br/seb/arquivos/pdf/book_volume_02 internet.pdf. Acesso em: 13 jun. 2018.

BROUSSEAU, Guy. Fundamentos e Métodos da Didáctica da Matemática. In: BRUN, J. Didática das Matemáticas. Tradução de: Maria José Figueiredo. Lisboa: Instituto Piaget, 1996a. Cap. 1. p. 35-113

CARMIGNIANI, Julie; FURHT, Borko. Augmented reality: an overview. In: FURHT, Borko. Handbook of augmented reality. New York: Springer, 2011. p. 3-46.

CHIUMMO, A. O Conceito de Área de Figuras Planas: Capacitação Para Professores do ensino fundamntal. 1998. 142f. (Dissertação Mestrado) - Programa de Estudos PósGraduação e Educação Matemática, PUC-SP, São Paulo, 1998. \disponível em: https://www.sapientia.pucsp.br/bitstream/handle/11517/2/Ana\%20Chiummo.pdf. Acesso em: 15 jan. 2018.

CORDEIRO, Felipe. Android SDK: O que é? Para que serve? Como usar? [201-?], Disponível em: https://www.androidpro.com.br/blog/android-studio/android-sdk/. Acesso em: 16 out. 2019.

COSTA, Rosa Maria M. E.; RIBEIRO, Marcos Wagner S. (org.). Aplicações de realidade virtual e aumentada. Porto Alegre: Sociedade Brasileira de Computação, 2009.

CREDER, Hélio. Instalações elétricas. Atualização e revisão: Luiz Sebastião Costa. Rio de Janeiro: LTC, 2016.

DANTAS, Alessandra Torrezan Sanches; TEIXEIRA-OLIVEIRA, Márcia. Construção e Aplicação de Sequência Didática com Smartphone para Ensino de Biologia. Revista REAMEC, Cuiabá (MT), v. 8, n. 1, p. 194-210, janeiro-abril, 2020. Disponível em: https://periodicoscientificos.ufmt.br/ojs/index.php/reamec/article/view/9483/pdf. Acesso em: 13 jul. 2020.

DESENVOLVIMENTO DE JOGOS. 2018. Disponível em: http://desenvolvimentodejogos.wikidot.com/opengl. Acesso em: 15 ago. 2018.

DEVELOPER. Arquitetura da plataforma. [200-?]. Disponível em: https://developer.android.com/guide/platform. Acesso em: 15 jan. 2018.

DOUADY, Regine; PERRIN-GLORIAN, Marie-Jeanne. Un Processus d'apprentissage du Concept D'airede surface plane. Educational Studiesin Mathematics, New York, NY, v. 20, n. 4, p. 387-424, nov. 1989. ISSN 1573-0816. Disponível em: https://www.jstor.org/stable/3482315?seq=1\#page scan tab_contents. Acesso em: 15 jan. 2018 .

DUNCAN, Sandra de Aquino Maia. Uso de técnicas de realidade aumentada no ensino de pirâmide. 2014. 52 f. Dissertação (Mestrado em Matemática) - Centro de Ciência e Tecnologia. Laboratório de Ciências Matemáticas, Universidade Estadual do Norte Fluminense Darcy Ribeiro, Campos dos Goytacazes, 2014. Disponível em: http://uenf.br/posgraduacao/matematica/wp- 
content/uploads/sites/14/2017/09/28112014Sandra-de-Aquino-Maia-Duncan.pdf. Acesso em: 15 jan. 2018.

FACCO, Sonia Regina. Conceito de área, uma proposta de ensino-aprendizagem. 2003. 150 f. Dissertação (Mestrado em Educação Matemática) - Pontifícia Universidade Católica de São Paulo, PUC, São Paulo, 2003. Disponível em:

https://tede2.pucsp.br/bitstream/handle/11232/1/sonia\%20facco.pdf. Acesso em: 15 out. 2018.

FIORINI, Thiago Morais Sirio. Projeto de iluminação de ambientes internos especiais. Espirito Santo, 2006. Disponível em:

https:/hosting.iar.unicamp.br/lab/luz/ld/Arquitetural/interiores/projeto_de iluminacao_de am bientes_internos_especiais.pdf. Acesso em: 20 jul. 2018.

GASPAROTTO, Henrique Machado. Unity3: introdução ao desenvolvimento de games. 2014. Disponível em: https://www.devmedia.com.br/unity-3d-introducao-aodesenvolvimento-de-games/30653. Acesso em: 16 out. 2019.

GRUBER, Rafaelly et al. Magic memo: jogo da memória educativo infantil, um aplicativo android com realidade aumentada. In: CONGRESSO NACIONAL DE INOVAÇÃO E TECNOLOGIA, 2016., São Bento do Sul, Anais [...]. São Bento do Sul: INOVA, 2016. Disponível em: http://www.inova.ceplan.udesc.br/public/anais/2016/4736.pdf. Acesso em: 11 nov. 2018.

JAVA. [201-?]. Disponível em: https://www.java.com/pt_BR/download/faq/whatis java.xml. Acesso em: 11 out. 2019.

KIRNER, Claudio; TORI, Romero. Fundamentos de Realidade Aumentada. In: KIRNER, Claudio; TORI, Romero; SISCIUTTO, Robson (ed.). Fundamentos e tecnologia de realidade virtual e aumentada. Belém: SBC, 2006. p. 22-38. ISBN: 85-7669-068-3.

Disponível em:

http://www.ckirner.com/download/capitulos/Fundamentos_e_Tecnologia_de_Realidade_Virt ual e Aumentada-v22-11-06.pdf. Acesso em: 15 out. 2018.

LINDEMANN, Jânio Luís. Desenvolvimento de aplicação de realidade aumentada em dispositivos móveis. 2014. 64 f. Trabalho de Conclusão de Curso (Graduação em Sistema de Informação) - Centro Universitário Univates, Lajeado- RS, 2014. Disponível em: https://www.univates.br/bdu/bitstream/10737/580/1/2014JanioLuisLindemann.pdf. Acesso em: 11 set. 2018.

LUMINOTÉCNICA. [2009]. Disponível em:

http://joinville.ifsc.edu.br/ edsonh/Repositorio/PIP-

Projeto_e Instalacoes_Eletricas_Prediais/Material\% $20 \mathrm{de} \% 20 \mathrm{Aula} / \mathrm{Parte}$ II_Luminot $\% \mathrm{C} 3 \% \mathrm{~A}$ 9cnica/Apostilas/Apostila de Instala $\% \mathrm{C} 3 \% \mathrm{~A} 7 \% \mathrm{C} 3 \% \mathrm{~B} 5 \mathrm{es}$ El $\% \mathrm{C} 3 \% \mathrm{~A} 9 \mathrm{tricas}$ parte2.pdf.

Acesso em: 12 nov. 2017.

MEYER, Mauricio. A história do iOS. Oficina da Net, 2018. Disponível em: https://www.oficinadanet.com.br/post/17950-a-historia-do-ios. Acesso em: 16 out. 2019.

MOREIRA, Marli Duffes Donato. Revisitando Euclides para o ensino de áreas: uma proposta para as Licenciaturas. 2010. 165 f. Dissertação (Mestrado em Ensino de Matemática) 
- Universidade Federal do Rio de Janeiro, Rio de Janeiro, 2010. Disponível em: http://www.pg.im.ufrj.br/pemat/28\%20Marli\%20Moreira.pdf. Acesso em: 16 ago. 2018.

NUNES, José Messildo Viana. A Prática da argumentação como método de ensino: o caso dos conceitos de área e perímetro de figuras planas. Orientador: Saddo Ag Almouloud. 2011. 219 f. Tese (Doutorado em Educação Matemática) - Pontifícia Universidade Católica de São Paulo, São Paulo, 2011. Disponível em: https://tede2.pucsp.br/handle/handle/10891. Acesso em: 11 ago. 2018.

PEDROZA, Natan; NICOLAU, Marcos. Toque na tela: a revolução da tecnologia. In: CONGRESSO BRASILEIRO DE CIÊNCIAS DA COMUNICAÇÃO, 38., Rio de Janeiro, Anais [...]. Rio de Janeiro: Intercom, 2015. Disponível em: http://portalintercom.org.br/anais/nacional2015/resumos/R10-0425-1.pdf. Acesso em: 15 nov. 2018.

PEREIRA, Fabio. Personal digital assistant. Knoow.Net: enciclopédia temática. 2019. Disponível em: http:/www.abenge.org.br/cobenge/arquivos/12/artigos/199Fabiana\%20dos\%20Passos.pdf. Acesso em: 15 out. 2019.

RABARDEL, Pierre. Les hommes et les technologies: une approche cognitive des instruments contemporains. Paris: Armand Colin, 1995.

RIBEIRO, Marcos Wagner S.; ZORZAL, Ezequiel Roberto. Realidade Virtual e Aumentada: Aplicações e Tendências. Livro do Pré-Simpósio 2011. XIII Simpósio de Realidade Virtual e Aumentada. Uberlândia, Brasil, 2011.

SALAZAR, Jesus Victória Flores. Gênese Instrumental na interação com Cabri 3D: um estudo de transformações geométricas no espaço. Orientador: Saddo Ag Almouloud. 2009. 317 f. Tese (Doutorado em Educação Matemática) - Pontifícia Universidade Católica de São Paulo, São Paulo, 2009. Disponível em: https://tede2.pucsp.br/handle/handle/11397. Acesso em: 13 jun. 2016.

SANTOS, Maikon Cismoski dos. Renderização de cenas tridimensionais interativas em computadores com recursos gráficos limitados. Orientador: Hélio Pedrini. 2009. 112 f. Dissertação (Mestrado) - Programa de Pós-Graduação em Informática, Universidade Federal do Paraná, Curitiba, 2009. Disponível em: http://hdl.handle.net/1884/18410. Acesso em: 19 jul. 2016.

SANTOS, Maria Adélia Icó dos. Utilização da realidade aumentada no desenvolvimento de software educacional: um exemplo em alguns conceitos na Astronomia. 2015. $106 \mathrm{f}$. Dissertação (Mestrado em Computação Aplicada) - Universidade Estadual de Feira de Santana, Feira de Santana, 2015. Disponível em: https://www.btdea.ufscar.br/teses-edissertacoes/utilizacao-de-realidade-aumentada-no-desenvolvimento-de-softwareeducacional-um-exemplo-em-alguns-conceitos-na-astronomia. Acesso em: 19 jul. 2018.

SIGNIFICADOS de WhatsApp. 2015. não paginado. Disponível em: https://www.significados.com.br/whatsapp/. Acesso em: 20 out. 2018. 
SILVA, Allessio da. Realidade Aumentada: recurso multimidiático e sua contribuição no processo de ensino aprendizagem. 63 f. 2012. Monografia (Graduação em Computação) Centro de Ciências e Tecnologias, Universidade Estadual da Paraíba, João Pessoa, 2012.

SILVA, Josiane Carlota da; PASQUINI, Adriana Salvaterra. Plano Nacional da Educação 2011-2020, da conferência à aprovação: avanços e retrocessos no ensino superior.

Revista Cesumar - Ciências Humanas e Sociais Aplicadas, v. 18, n. 1, p. 83-103, jan./jun. 2013. Disponível em:

https://periodicos.unicesumar.edu.br/index.php/revcesumar/article/viewFile/2861/2133.

Acesso em: 13 jul. 2018.

SILVA, Luiz Paulo Moreira. Área do cilindro. Mundo da Educação. [201-]. Disponível em: https://mundoeducacao.bol.uol.com.br/matematica/area-cilindro.htm. Acesso em: 13 jul. 2018.

SILVA, Sheila Paulino e. Phronesis e noesis em Platão: a excelência do pensamento filosófico. 2016. 236 f. Tese (Doutorado em Filosofia) - Programa de Pós-Graduação em Filosofia, Universidade de São Paulo, São Paulo, 2016. Disponível em:

https://teses.usp.br/teses/disponiveis/8/8133/tde-18032016105356/publico/2016 SheilaPaulinoESilva VCorr.pdf. Acesso em: 11 set. 2018.

SILVA, Wender Antônio da et al. Uma arquitetura para distribuição de ambientes virtuais de realidade aumentada. RBIE, Uberlândia, v. 16, n. 3, 2008. DOI:

http://dx.doi.org/10.5753/rbie.2008.16.03.\%25. ISSN 2317-6121. Disponível em:

http://www.br-ie.org/pub/index.php/rbie/article/view/39/33. Acesso em: 13 jul. 2018.

SWEET home. 2019. Disponível em: http://www.sweethome3d.com/pt/. Acesso em: 03 set. 2019.

TECHOPEDIA. Ultra Mobile PC (UMPC). [201-?]. Disponível em:

https://www.techopedia.com/definition/2982/ultra-mobile-pc-umpc. Acesso em: 12 out. 2019.

VICENTINI, Wilson Bittencourt et al. Realidade aumentada: interface computacional de geração de ambientes virtuais de aprendizagem para portadores de necessidades especiais (surdos e mudos). In: SEMINARIO NACIONAL DE BIBLIOTECAS UNIVERSITÁRIAS, 14. 2006., Salvador. Anais [...]. Salvador: SNBU, 2006. Disponível em: http://bdpi.usp.br/item/001552958. Acesso em: 11 jun. 2017.

ZUÑIGA TORRES, Juan Carlos. Uma metodologia para o desenvolvimento de aplicações de realidade aumentada em telefones celulares utilizando dispositivos sensores.

Orientador: Sergio Takeo Kofuji. 2008. 94 f. Dissertação (Mestrado em Engenharia) Universidade de São Paulo, São Paulo, 2008. DOI: 10.11606/D.3.2008.tde-18022009-165517. Disponível em: http://www.teses.usp.br/teses/disponiveis/3/3142/tde-18022009-165517/ptbr.php. Acesso em: 18 jul. 2017. 


\section{NOTAS}

\section{AGRADECIMENTOS}

Agradecemos a Universidade Federal do Maranhão (UFMA) pelo apoio no decorrer do desenvolvimento da pesquisa de doutorado da primeira autora que originou o artigo aqui apresentado.

\section{FINANCIAMENTO}

Não houve financiamento.

\section{CONTRIBUIÇÕES DE AUTORIA}

Resumo/Abstract/Resumen: Kayla Rocha Braga, José Messildo Viana Nunes Introdução: Kayla Rocha Braga/José Messildo Viana Nunes

Referencial teórico: Kayla Rocha Braga, José Messildo Viana Nunes

Análise de dados: Kayla Rocha Braga, José Messildo Viana Nunes

Discussão dos resultados: Kayla Rocha Braga, José Messildo Viana Nunes

Conclusão e considerações finais: Kayla Rocha Braga, José Messildo Viana Nunes

Referências: Kayla Rocha Braga, José Messildo Viana Nunes

Revisão do manuscrito: José Messildo Viana Nunes

Aprovação da versão final publicada: Kayla Rocha Braga, José Messildo Viana Nunes

\section{CONFLITOS DE INTERESSE}

Os autores declararam não haver nenhum conflito de interesse de ordem pessoal, comercial, acadêmico, político e financeiro referente a este manuscrito.

\section{DISPONILIDADE DE DADOS DE PESQUISA}

Informamos que os dados foram apresentados no próprio artigo. Podemos disponibilizar ainda todos os dados, códigos de programas e outros materiais que foram gerados na pesquisa.

\section{CONSENTIMENTO DE USO DE IMAGEM}

Não se aplica.

\section{COMO CITAR - ABNT}

BRAGA, Kayla Rocha; NUNES, José Messildo Viana. Realidade aumentada e o cálculo de medida de área no ensino superior. REAMEC - Rede Amazônica de Educação em Ciências e Matemática. Cuiabá, v. 9, n. 1, e21004, janeiro-abril, 2021. DOI: $10.26571 /$ reamec.v9i1.11273.

\section{COMO CITAR - APA}

Braga, K. R.; Nunes, J. M. V. (2021). Realidade aumentada e o cálculo de medida de área no ensino superior. REAMEC - Rede Amazônica de Educação em Ciências e Matemática, 9 (1), e21004. DOI: 10.26571/reamec.v9i1.11273.

\section{LICENÇA DE USO}

Licenciado sob a Licença Creative Commons Attribution-NonCommercial 4.0 International (CC BY-NC 4.0). Esta licença permite compartilhar, copiar, redistribuir o manuscrito em qualquer meio ou formato. Além disso, permite adaptar, remixar, transformar e construir sobre o material, desde que seja atribuído o devido crédito de autoria e publicação inicial neste periódico.

\section{DIREITOS AUTORAIS}

Os direitos autorais são mantidos pelos autores, os quais concedem à Revista REAMEC - Rede Amazônica de Educação em Ciências e Matemática - os direitos exclusivos de primeira publicação. Os autores não serão remunerados pela publicação de trabalhos neste periódico. Os autores têm autorização para assumir contratos adicionais separadamente, para distribuição não exclusiva da versão do trabalho publicada neste periódico (ex.: publicar em repositório institucional, em site pessoal, publicar uma tradução, ou como capítulo de livro), com reconhecimento de autoria e publicação inicial neste periódico. Os editores da Revista têm o direito de proceder a ajustes textuais e de adequação às normas da publicação. 


\section{PUBLISHER}

Universidade Federal de Mato Grosso. Programa de Pós-graduação em Educação em Ciências e Matemática (PPGECEM) da Rede Amazônica de Educação em Ciências e Matemática (REAMEC). Publicação no Portal de Periódicos UFMT. As ideias expressadas neste artigo são de responsabilidade de seus autores, não representando, necessariamente, a opinião dos editores ou da referida universidade.

\section{EDITOR}

Dailson Evangelista Costa (D)

\section{HISTÓRICO}

Submetido: 9 de outubro de 2020.

Aprovado: 16 de novembro de 2020

Publicado: 15 de janeiro de 2021. 